\title{
Thermodynamic and Spectroscopic Studies of
}

\section{Lanthanides(III) Complexation with Polyamines in}

\section{Dimethyl Sulfoxide}

\author{
P.Di Bernardo*, ${ }^{a}$ P.L. Zanonato, ${ }^{a}$ A. Melchior, ${ }^{b}$ R. Portanova, ${ }^{b}$ \\ M. Tolazzi, ${ }^{b}$ G.R. Choppin ${ }^{* c}$ and Z. Wang $^{d}$ \\ ${ }^{\mathrm{a}}$ Dipartimento di Scienze Chimiche, Università di Padova, Via Marzolo 1,
} 35131 Padova, ITALY

${ }^{\mathrm{b}}$ Dipartimento di Scienze e Tecnologie Chimiche, Università di Udine, Via del Cotonificio 108, 33100 Udine, ITALY

${ }^{\mathrm{c}}$ Department of Chemistry, The Florida State University, Tallahassee, FL 32306-3006 USA

${ }^{\mathrm{d}}$ Pacific Northwest National laboratory, Richland, WA 99352 USA

*Corresponding authors:

P. Di Bernardo, plinio.dibernardo@unipd.it; G.R.Choppin, choppin@chem.fsu.edu 
Supplementary material, Figures S1 - S16 


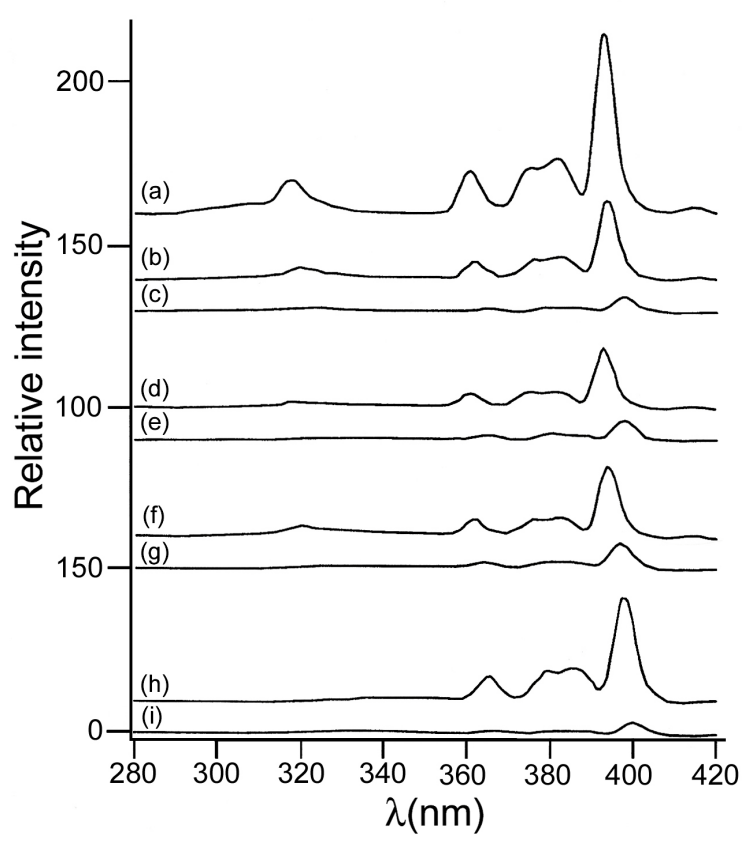

Figure S1. Excitation spectra of $\mathrm{Eu}^{3+} 0.02 \mathrm{~mol} \mathrm{dm}^{-3}$ (a) and $\mathrm{Eu}^{3+}$ complexes with amines: dien (b and c), trien (d and e), tren ( $\mathrm{f}$ and $\mathrm{g}$ ) and tetren ( $\mathrm{h}$ and i) at different $\mathrm{Eu}^{3+}$ :amine ratios in DMSO. [ $\left.\mathrm{Eu}^{3+}\right]$ :amine $=1: 0.80$ (b), 1:4.7 (c); 1:0.85 (d), 1: 11.0 (e); 1:1.25 (f), 1:8.0 (g); 1:0.67 (h), 1:3.0 (i). $\quad \lambda$ em $=616.0 \mathrm{~nm}$. Offset to the intensity: 160 (a), 140 (b), 130 (c), 100 (d), 90 (e), 60 (f), 50 (g), 10(h) and 0 (i).

\section{FIGURE S1}




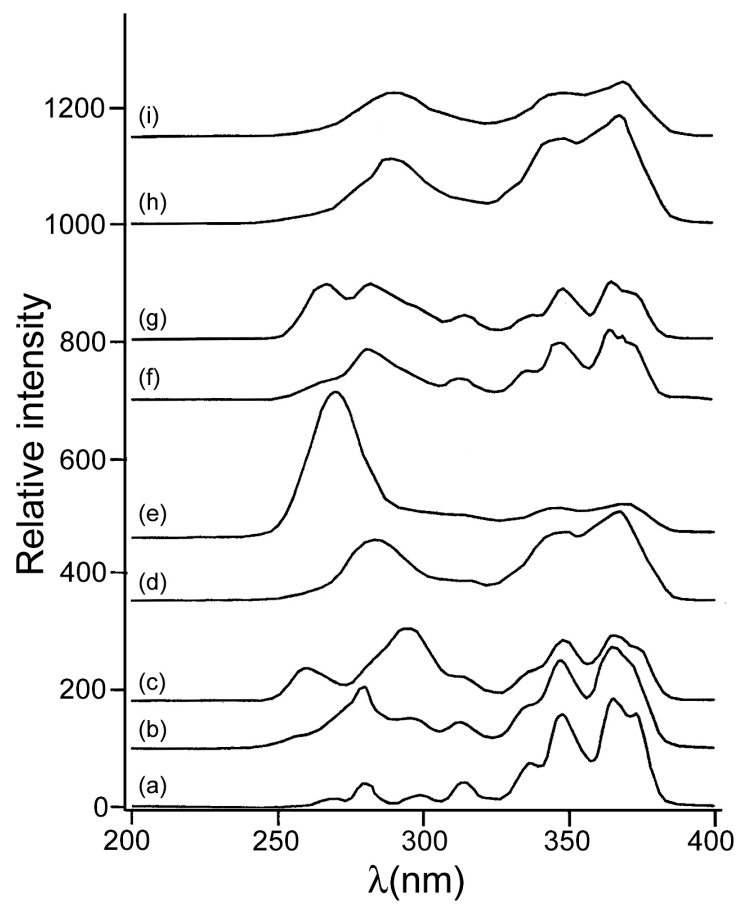

Figure S2. Excitation spectra of $\mathrm{Tb}^{3+} 0.1 \mathrm{~mol} \mathrm{dm}^{-3}$ (a) and $\mathrm{Tb}^{3+}$ complexes with amines: dien (b and c), trien (d and e), tren (f and $\mathrm{g}$ ) and tetren (h and i) at different $\mathrm{Tb}^{3+}$ :amine ratios in DMSO. $\left[\mathrm{Tb}^{3+}\right]$ :amine $=1: 0.8$ (b), 1:13.8 (c); 1:0.8 (d), 1:10 (e); 1:0.8 (f), 1:7.6 (g); 1:0.8 (h), 1:2.5 (i). $\quad \lambda_{\text {em }}=544.5 \mathrm{~nm}$. Offset to the intensity: 1150 (i), 1000 (h), 800 (g), 710 (f), 460 (e), 350 (d), 180 (c), 100 (b) and 0 (a).

\section{FIGURE S2}




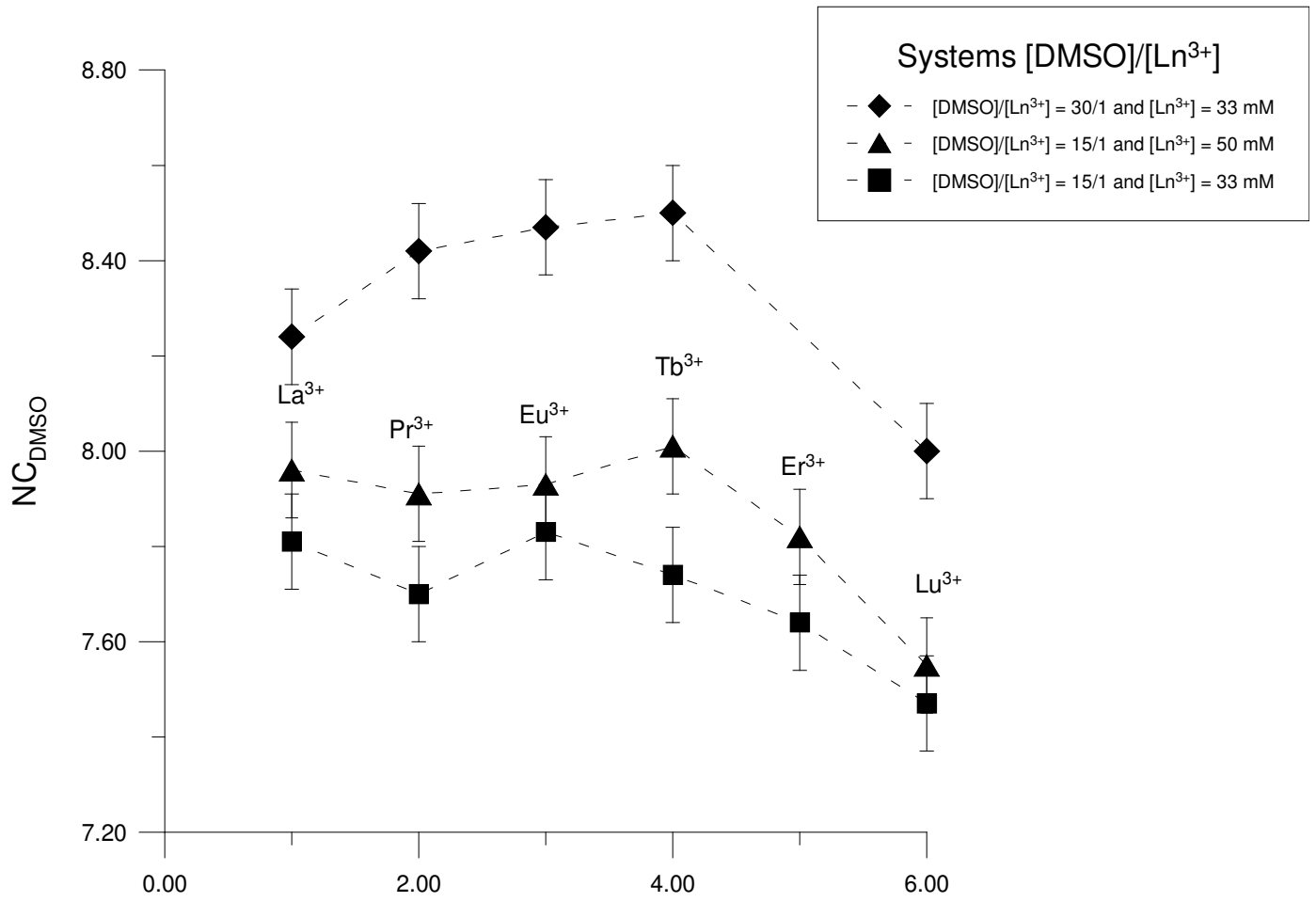

Figure S3. The mean number of molecules of DMSO coordinated to the metal ions in acetonitrile (AN) containing small amounts of DMSO.

\section{FIGURE S3}

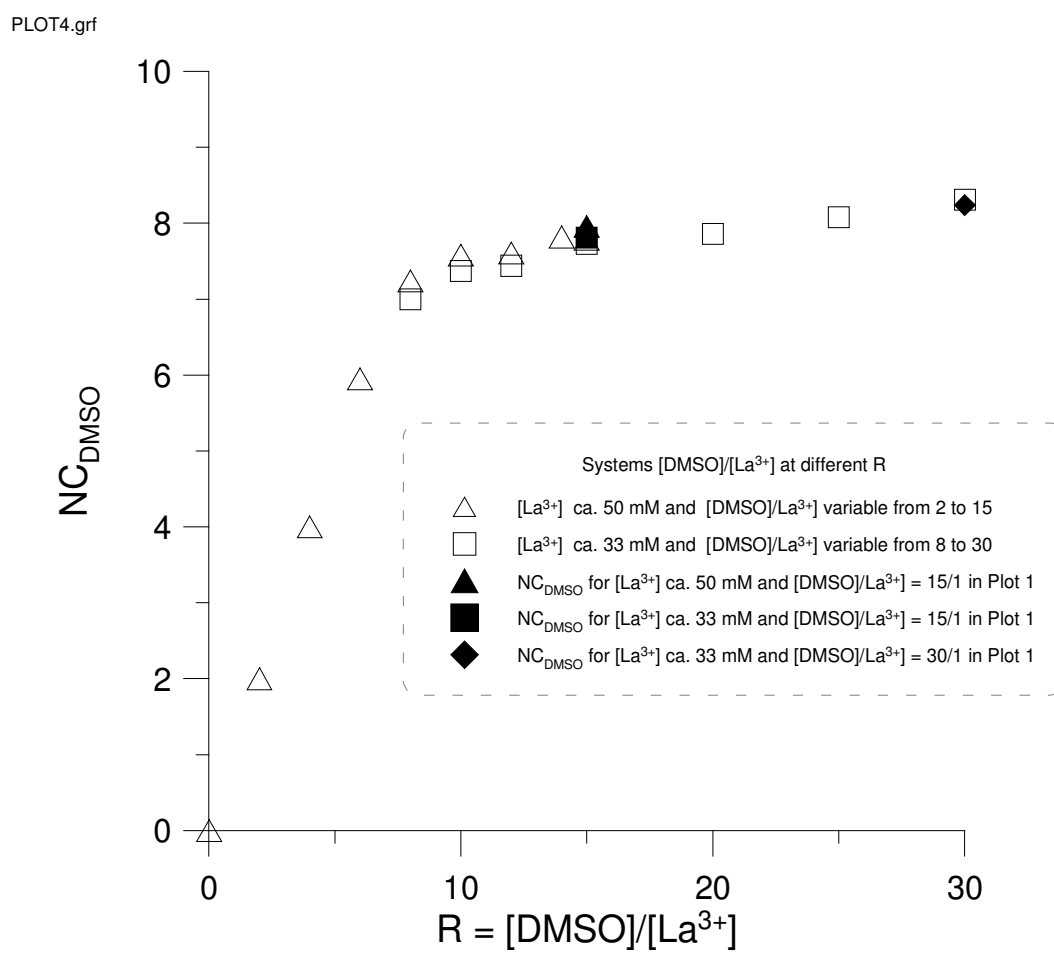

Figure S4. The mean number of molecules of DMSO coordinated to the lanthanum(III) in acetonitrile (AN) containing small amounts of DMSO. 


\section{FIGURE S4}

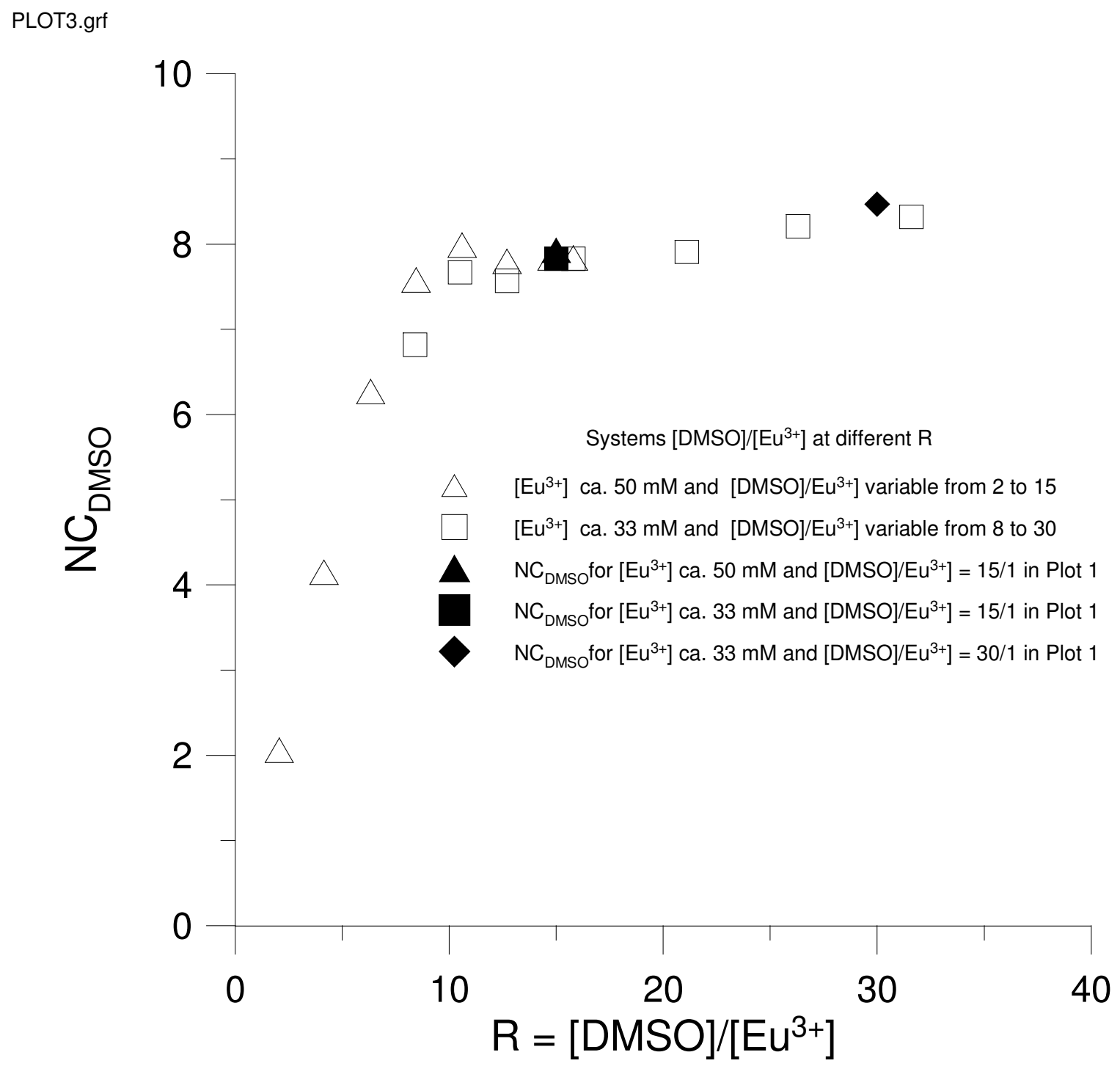

Figure S5. The mean number of molecules of DMSO coordinated to the europium(III) in acetonitrile (AN) containing small amounts of DMSO.

\section{FIGURE S5}




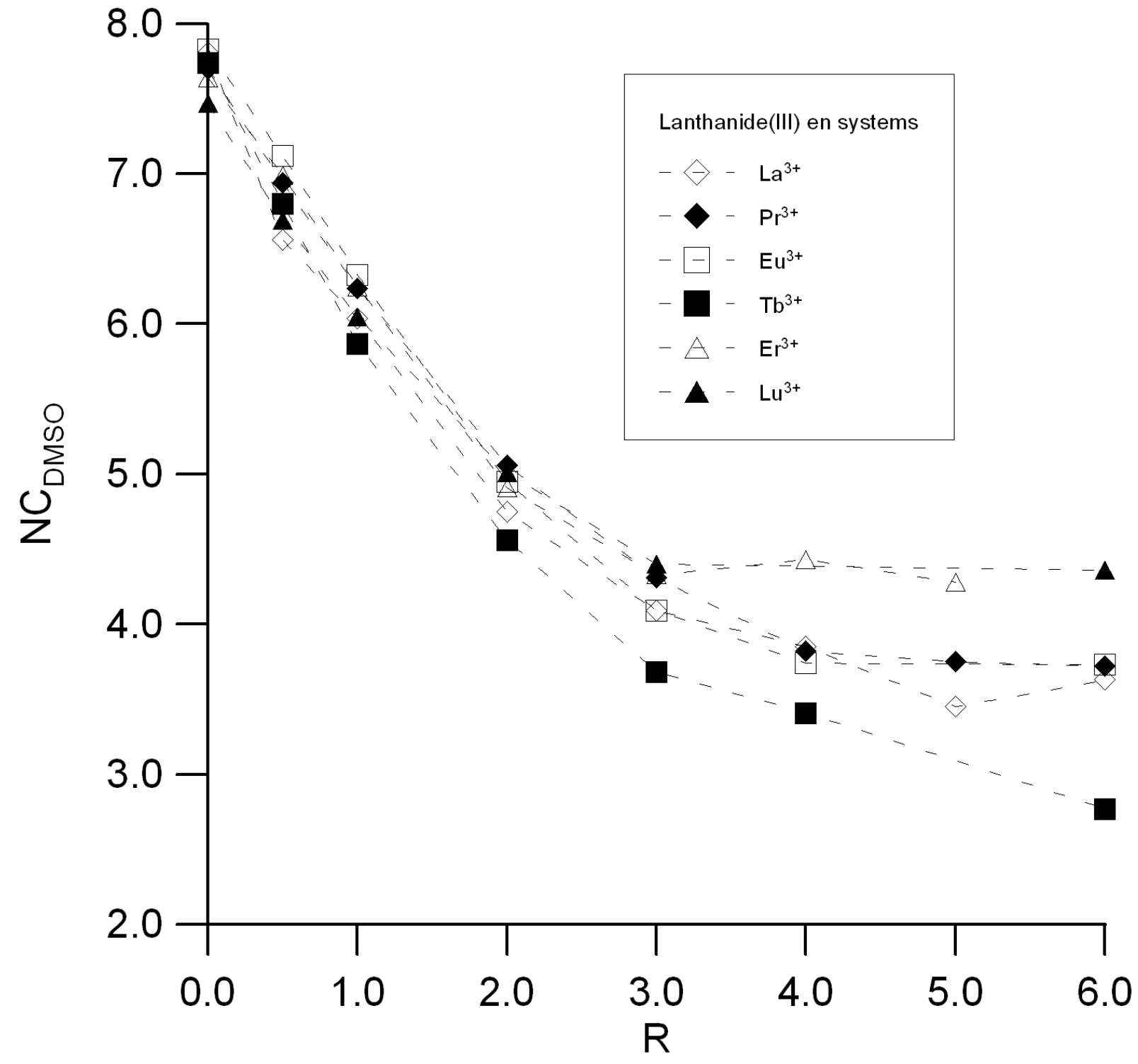

Figure S6. The Changes of $\mathrm{NC}_{\mathrm{DMSO}}$ with $\mathrm{R}$ ([amine]/[metal]) for the systems $\mathrm{Ln}^{3+} /$ ethylenediamine (en).

FIGURE S6 


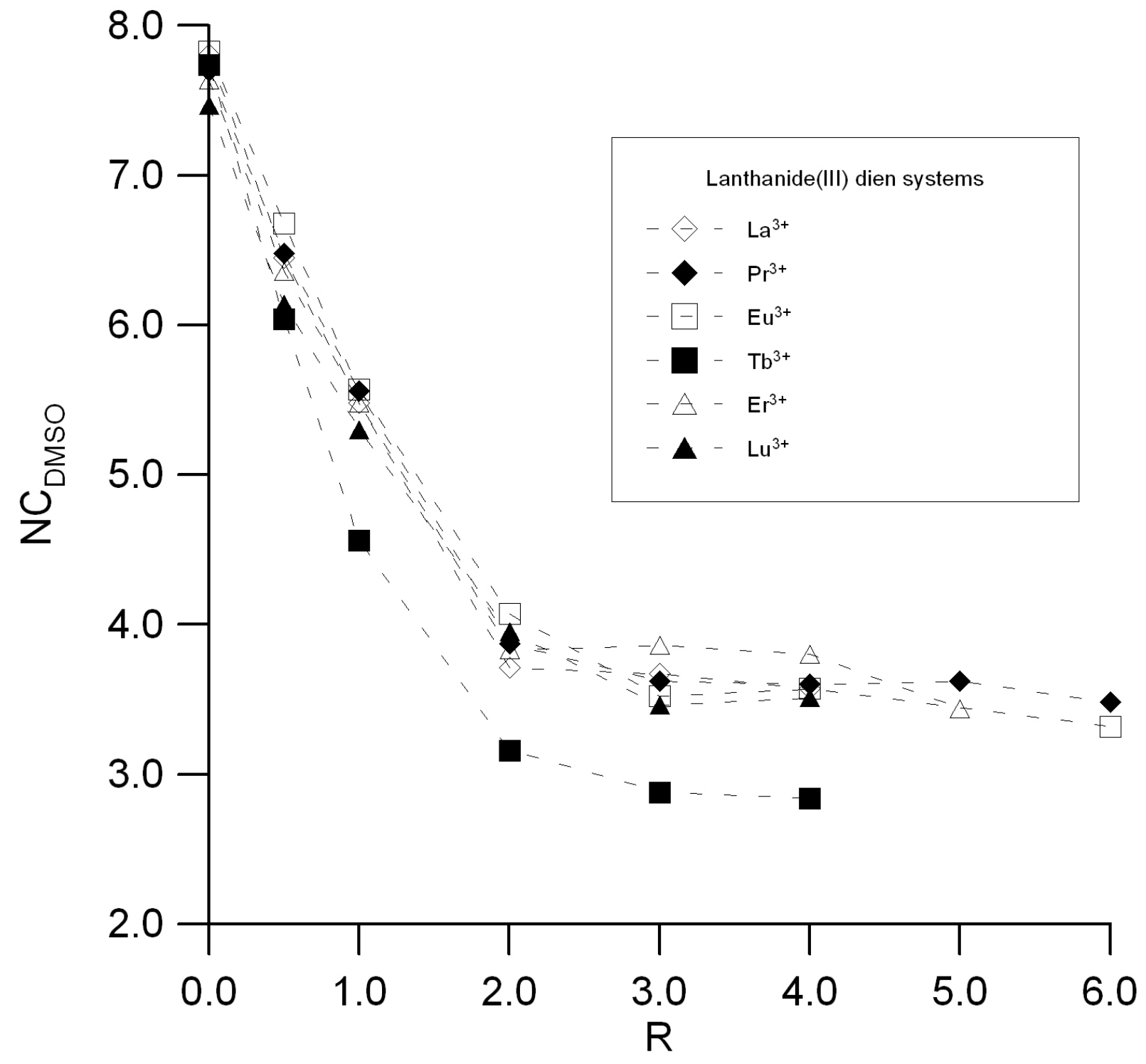

Figure S7. The Changes of $\mathrm{NC}_{\mathrm{DMSO}}$ with $\mathrm{R}$ ([amine]/[metal]) for the systems $\mathrm{Ln}^{3+} /$ diethylenetriamine (dien).

FIGURE S7 


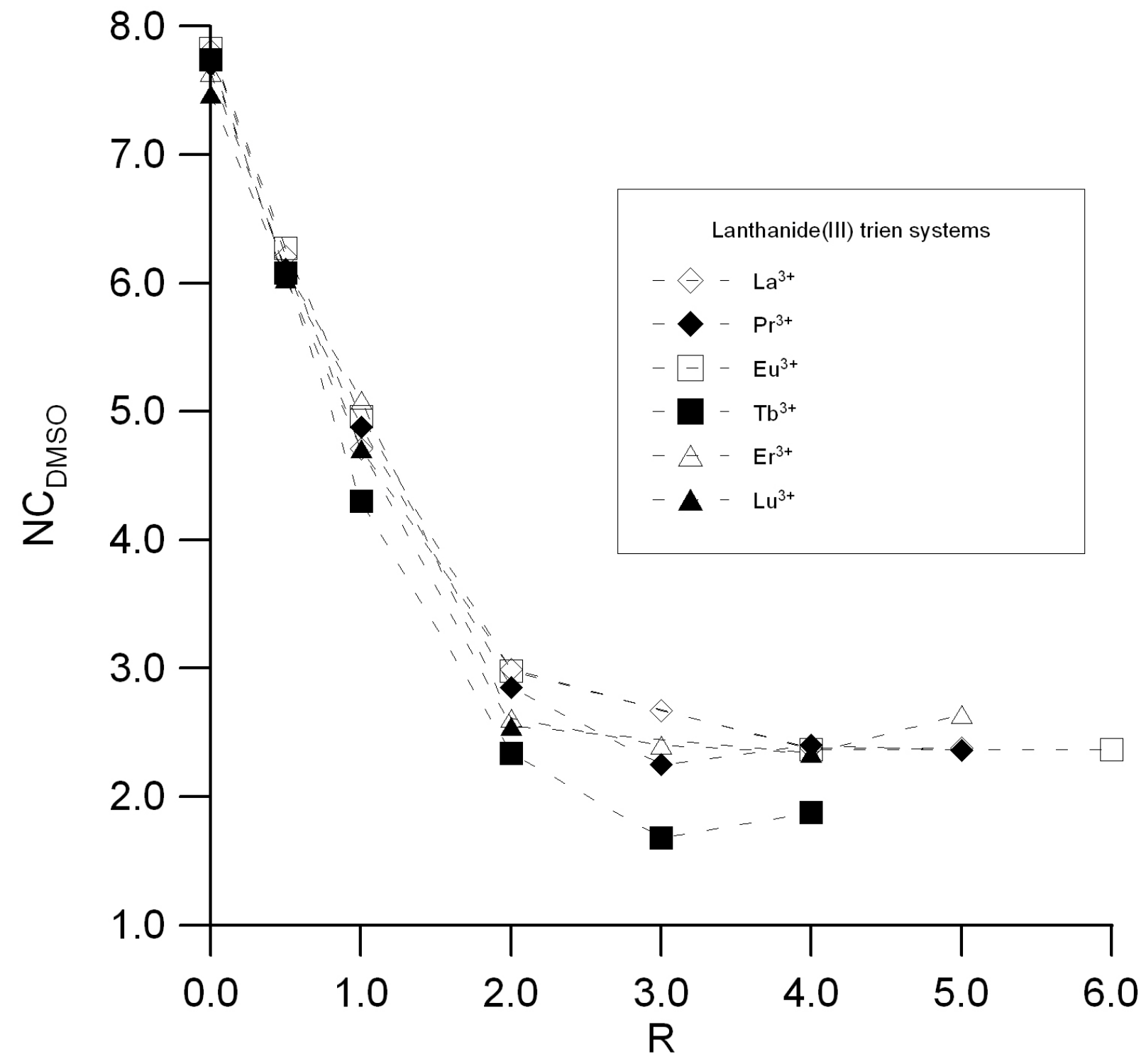

Figure S8. The Changes of $\mathrm{NC}_{\mathrm{DMSO}}$ with $\mathrm{R}$ ([amine]/[metal]) for the systems $\mathrm{Ln}^{3+} /$ triethylenetetramine (trien).

FIGURE S8 


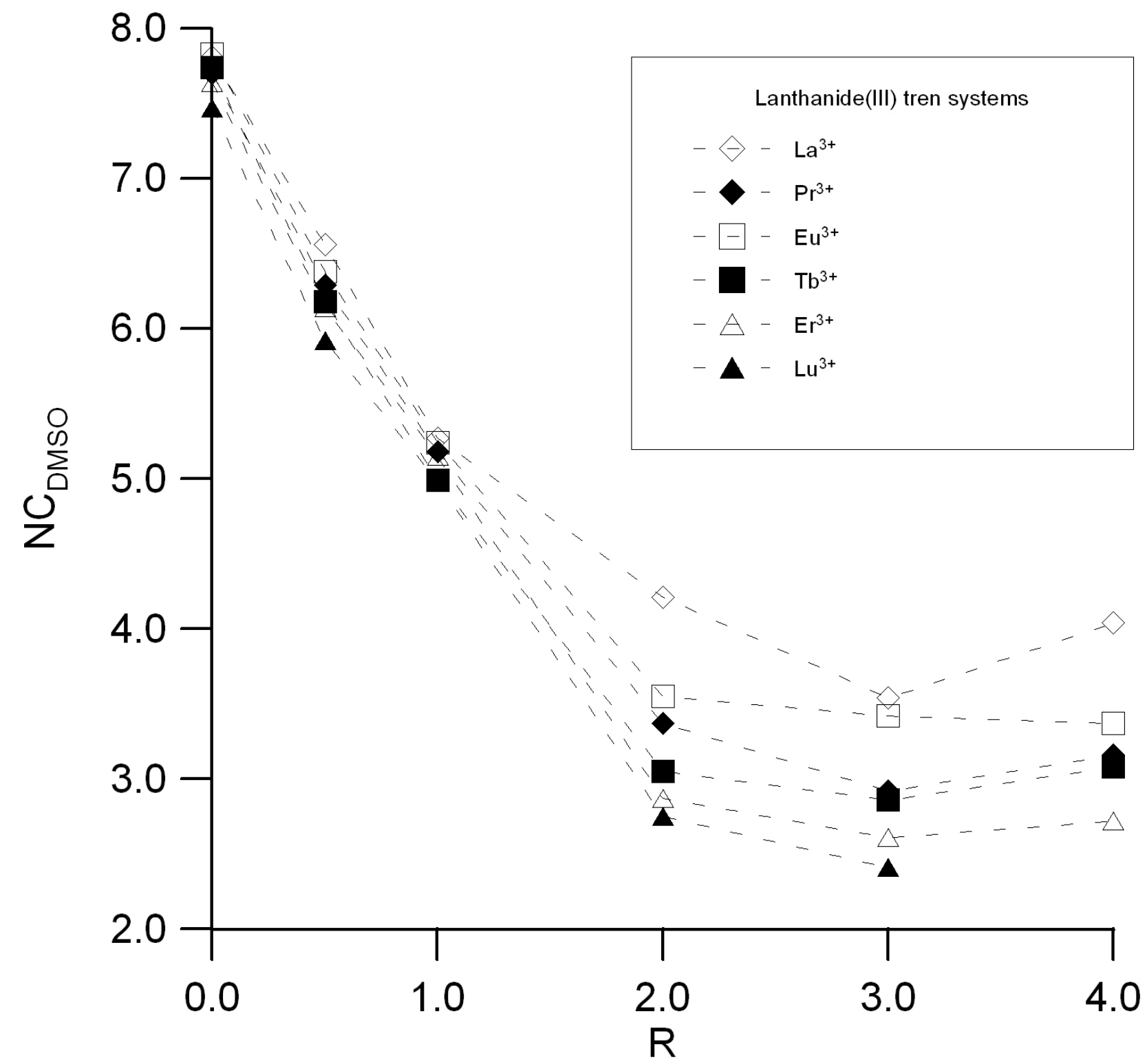

Figure S9. The Changes of $\mathrm{NC}_{\mathrm{DMSO}}$ with $\mathrm{R}$ ([amine]/[metal] ) for the systems $\mathrm{Ln}^{3+} / \operatorname{tris}(2$-aminoethyl)amine (tren).

FIGURE S9 


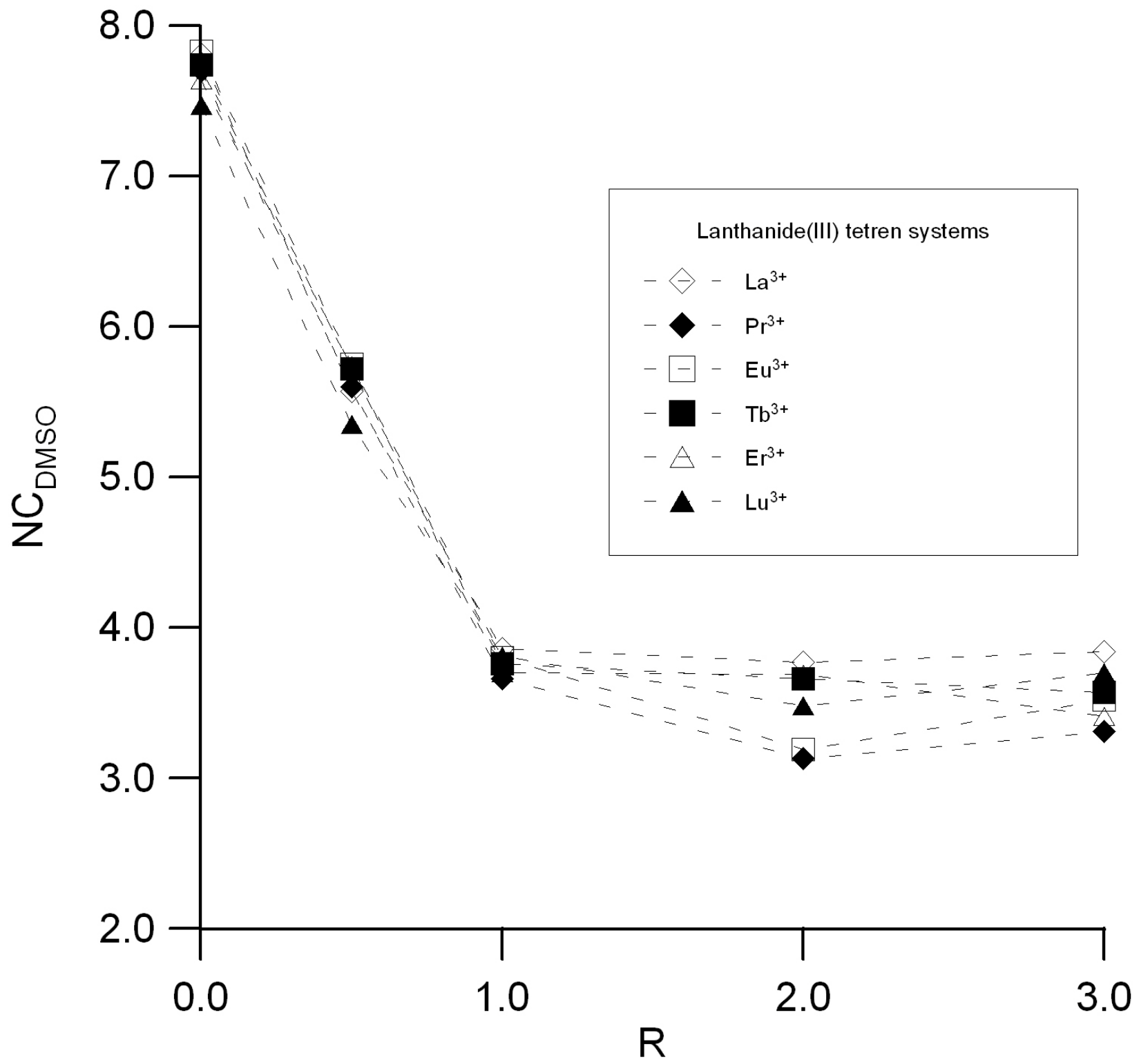

Figure S10. The Changes of $\mathrm{NC}_{\mathrm{DMSO}}$ with $\mathrm{R}\left(\left[\right.\right.$ amine]/[metal]) for the systems $\mathrm{Ln}^{3+} /$ tetraethylenepentamine (tetren).

FIGURE S10 



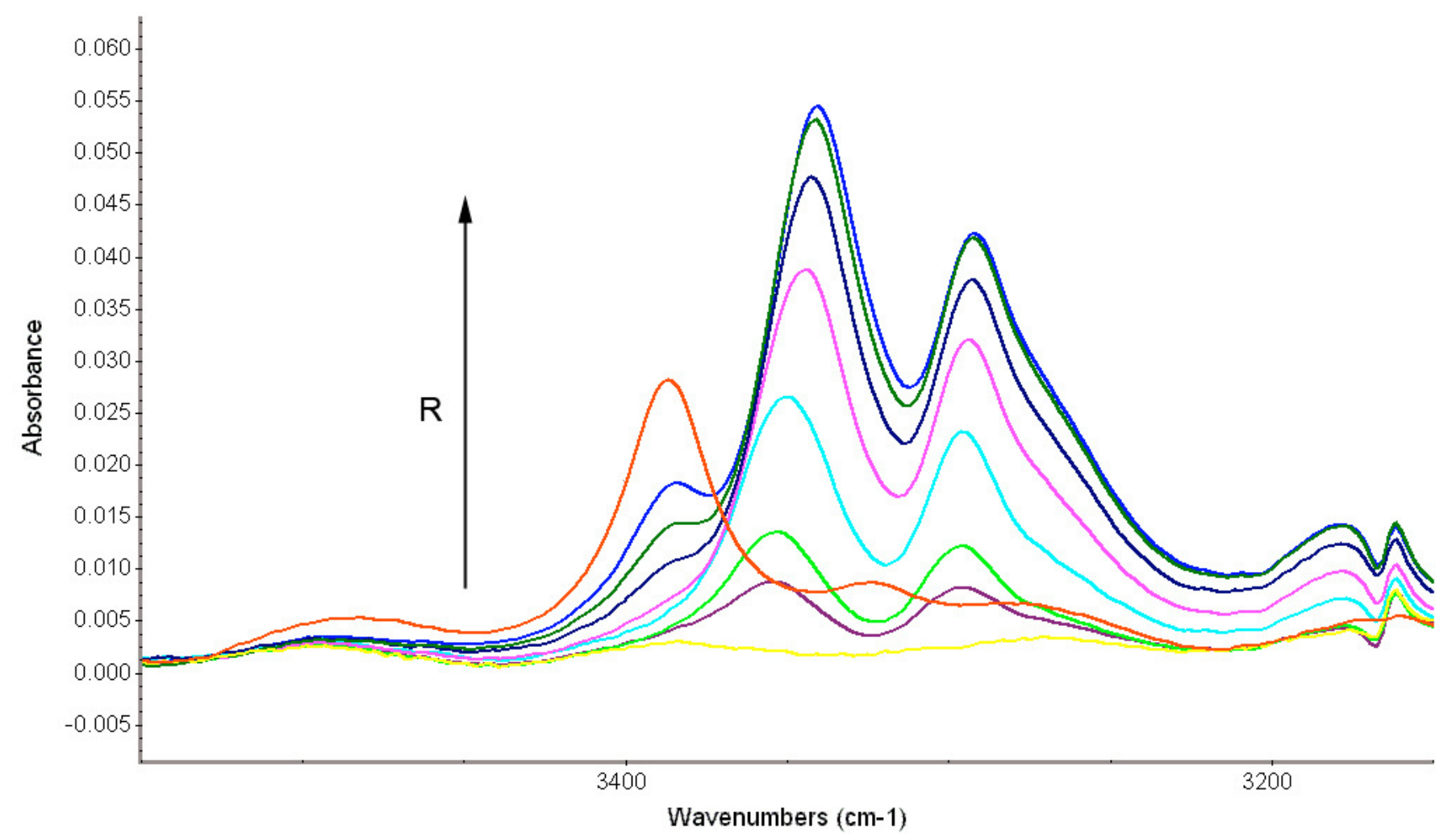

System La/en: $\left[\mathrm{La}^{3+}\right] \sim 33 \mathrm{mmol} \mathrm{dm}{ }^{-3} ; \mathrm{R}=[\mathbf{e n}] /\left[\mathrm{La}^{3+}\right]=0,0.5,1.0,2.0,3.0 ; 4.0,5.0,6.0$. Red spectrum: solution $198 \mathrm{mmol}$ $\mathrm{dm}^{-3}$ of en in AN.

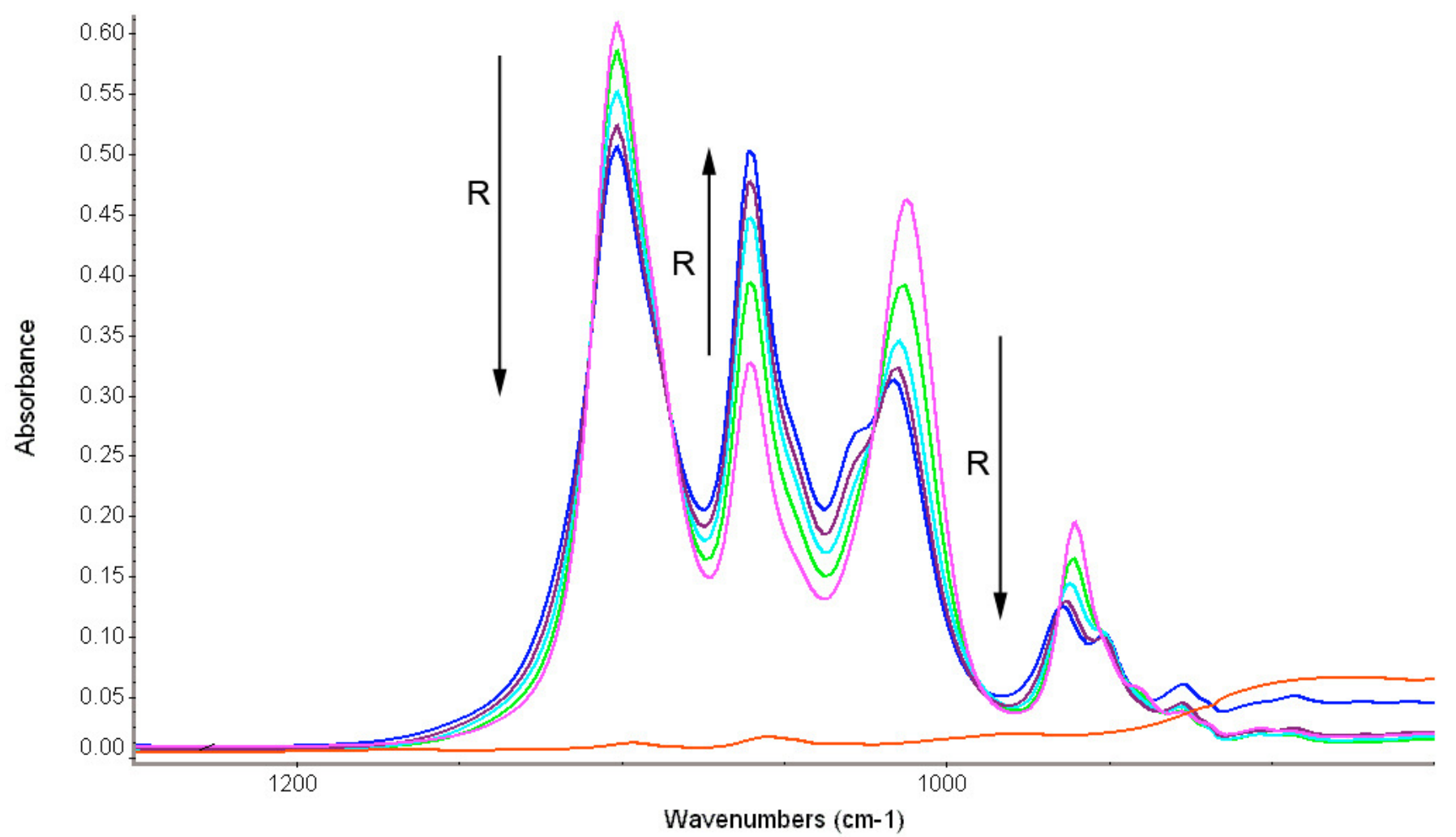

Figure S11. FT-IR spectra of $\mathrm{La}^{3+} / \mathbf{e n}$ system in the $1200-850 \mathrm{~cm}^{-1}$ region for solutions containing $\left[\mathrm{La}^{3+}\right] \approx$ $33 \mathrm{mmol} \mathrm{dm}^{-3}$ and increasing concentrations of en. $\mathrm{R}=[\mathbf{e n}] /\left[\mathrm{La}^{3+}\right]=0,0.5,1.0,2.0,3.0 ; 4.0,5.0$, 6.0. Red spectrum: solution $198 \mathrm{mmol} \mathrm{dm}^{-3}$ of en in AN. 


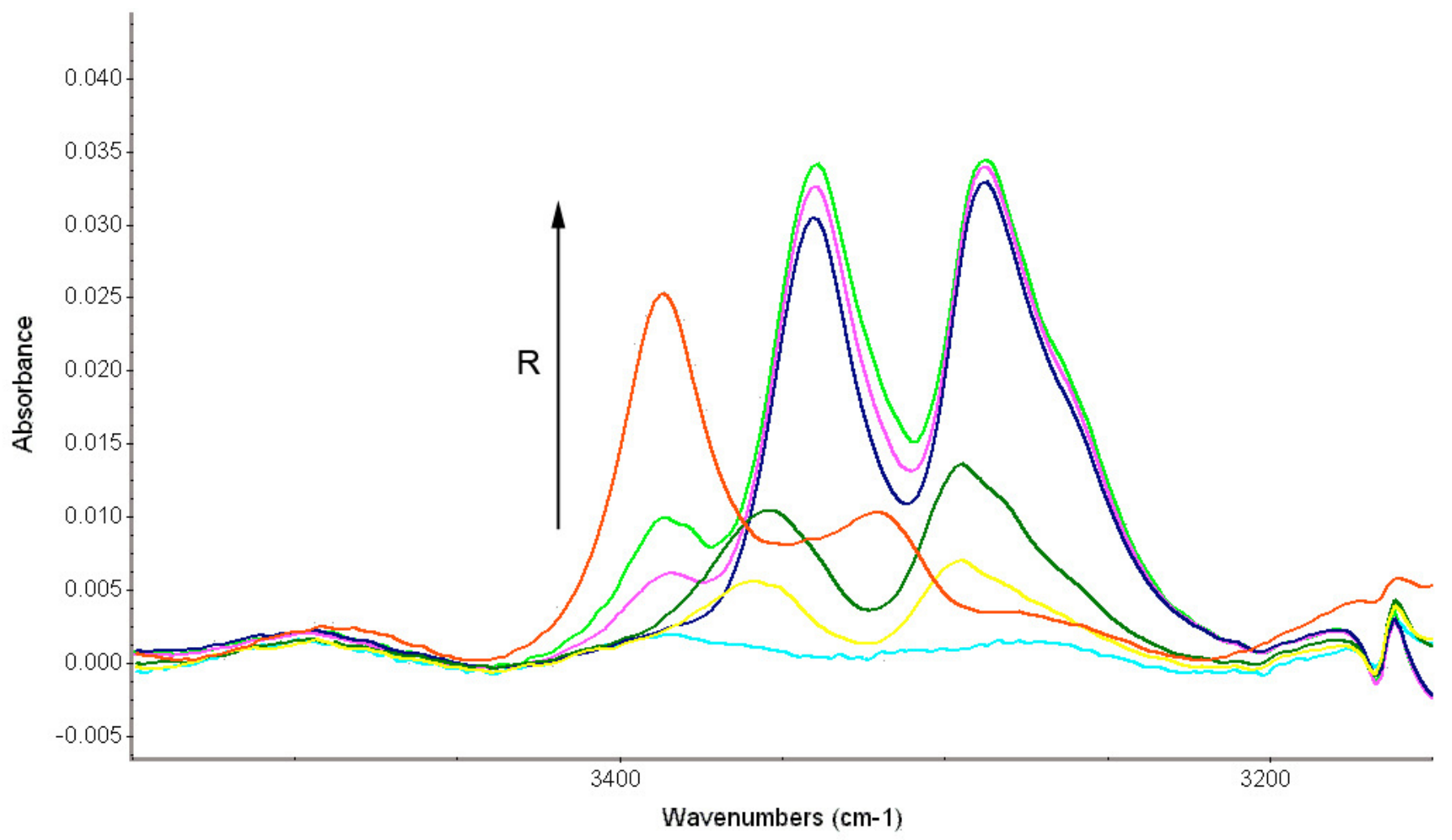

System La/dien: $\left[\mathrm{La}^{3+}\right] \sim 33 \mathrm{mmol} \mathrm{dm}{ }^{-3} ; \mathrm{R}=[\mathbf{d i e n}] /\left[\mathrm{La}^{3+}\right]=0.0,0.5,1.0,2.0,3.0,4.0$. Red spectrum: solution $198 \mathrm{mmol} \mathrm{dm}^{-3}$ of dien in AN.

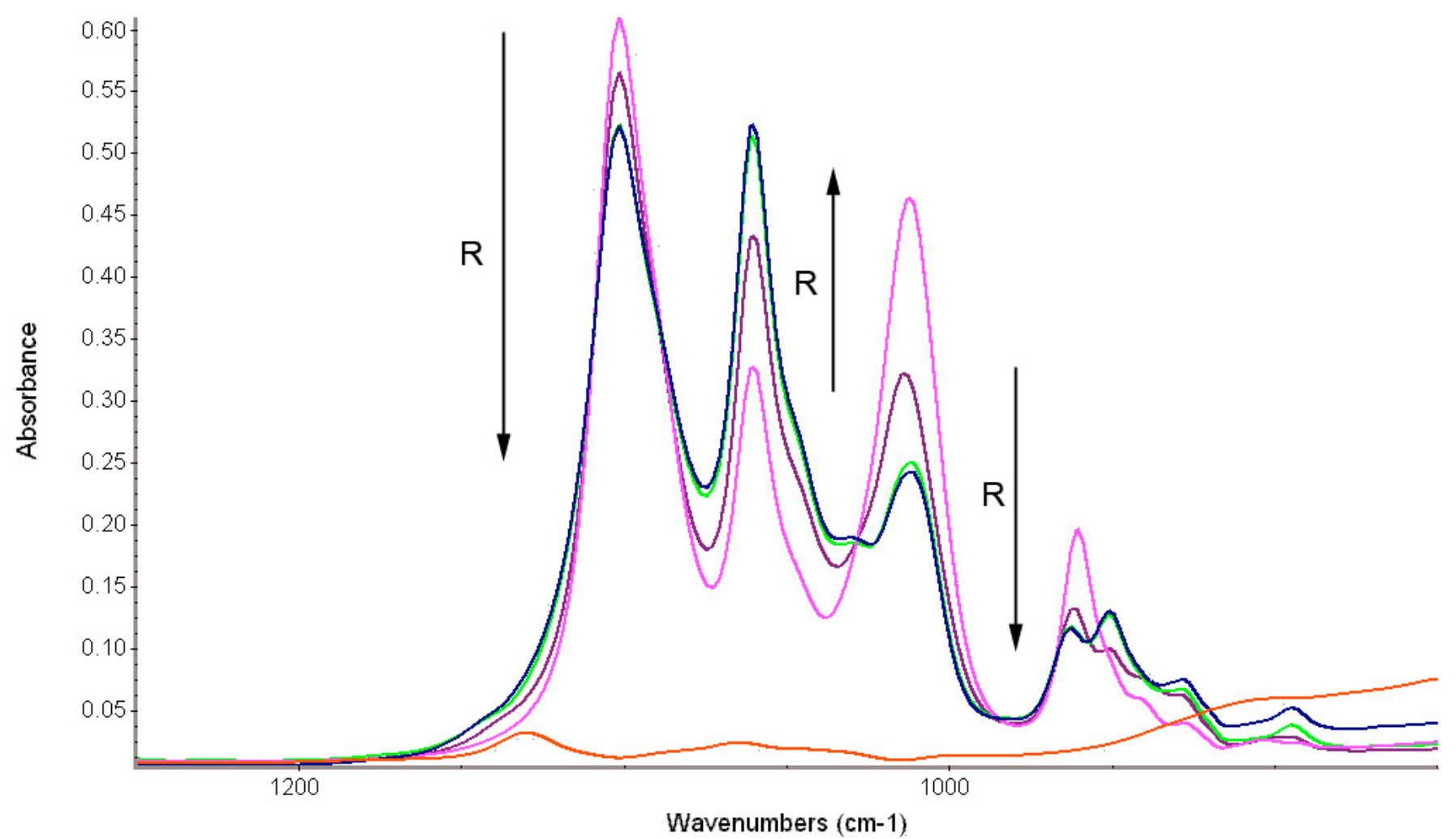

System La/dien: $\left[\mathrm{La}^{3+}\right] \sim 33 \mathrm{mmol} \mathrm{dm}{ }^{-3} ; \mathrm{R}=[$ dien $] /\left[\mathrm{La}^{3+}\right]=0.0,1.0,2.0,4.0$. Red spectrum: solution 198 mmol dm $\mathrm{dm}^{-3}$ of dien in AN.

FIGURE S12 


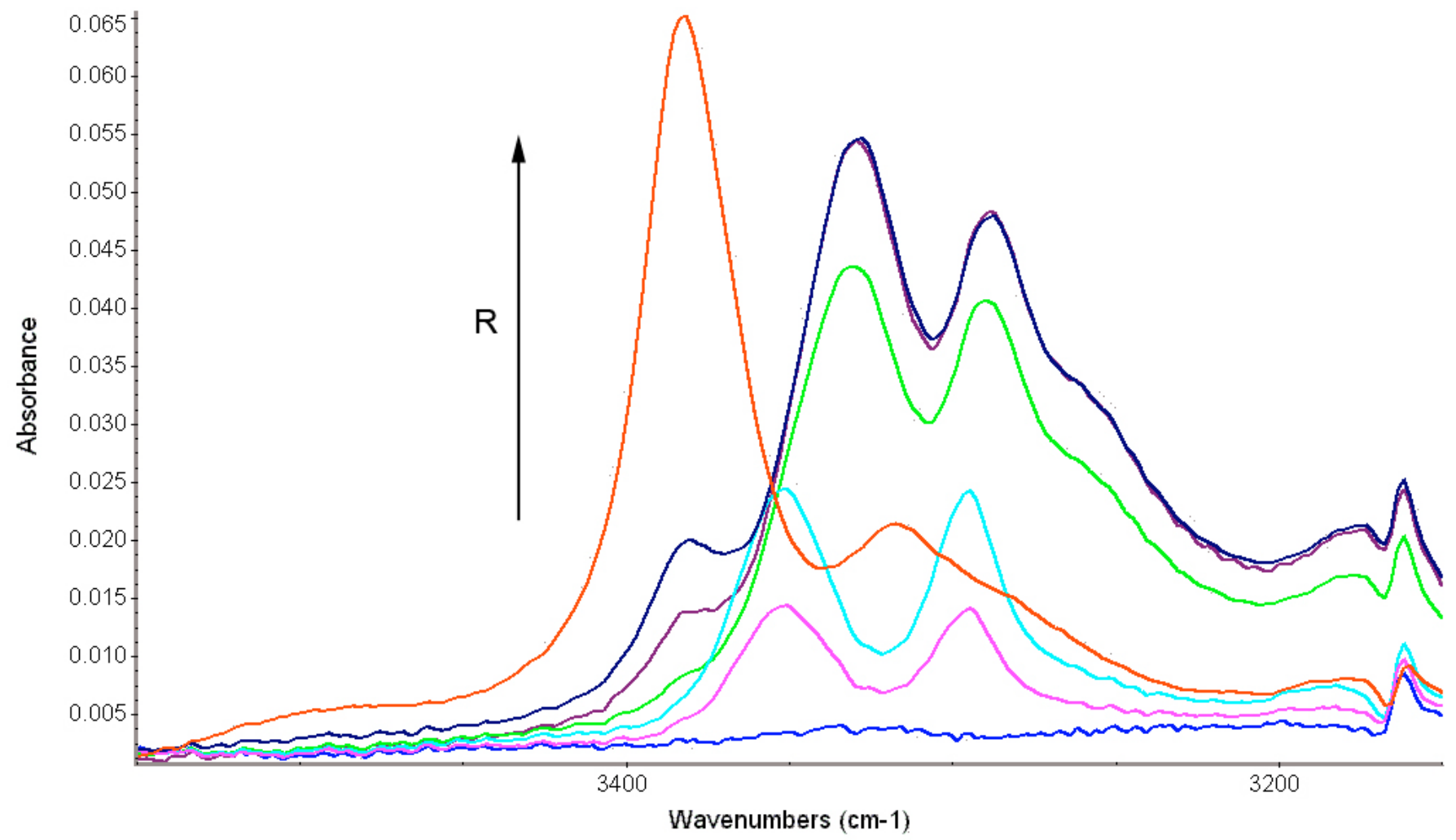

System La/tren: $\left[\mathrm{La}^{3+}\right] \sim 33 \mathrm{mmol} \mathrm{dm}{ }^{-3} ; \mathrm{R}=[\operatorname{tren}] /\left[\mathrm{La}^{3+}\right]=0,0.5,1.0,2.0,3.0,4.0$. Red spectrum: solution $333 \mathrm{mmol} \mathrm{dm}{ }^{-3}$ of tren in AN.

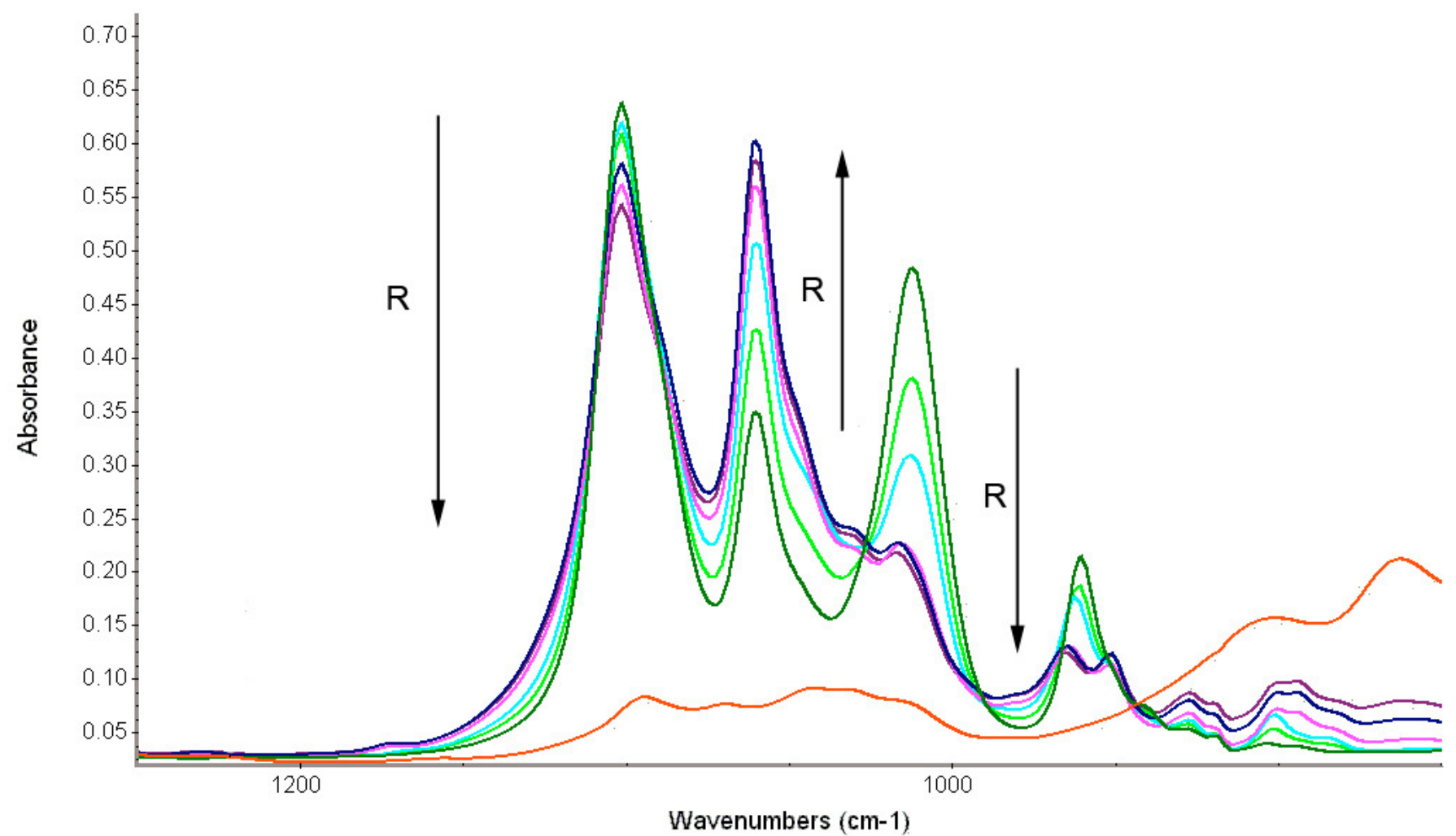

System La/tren: $\left[\mathrm{La}^{3+}\right] \sim 33 \mathrm{mmol} \mathrm{dm}{ }^{-3} ; \mathrm{R}=[$ tren $] /\left[\mathrm{La}^{3+}\right]=0,0.5,1.0,2.0,3.0,4.0$. Red spectrum: solution $333 \mathrm{mmol} \mathrm{dm}^{-3}$ of tren in AN. 


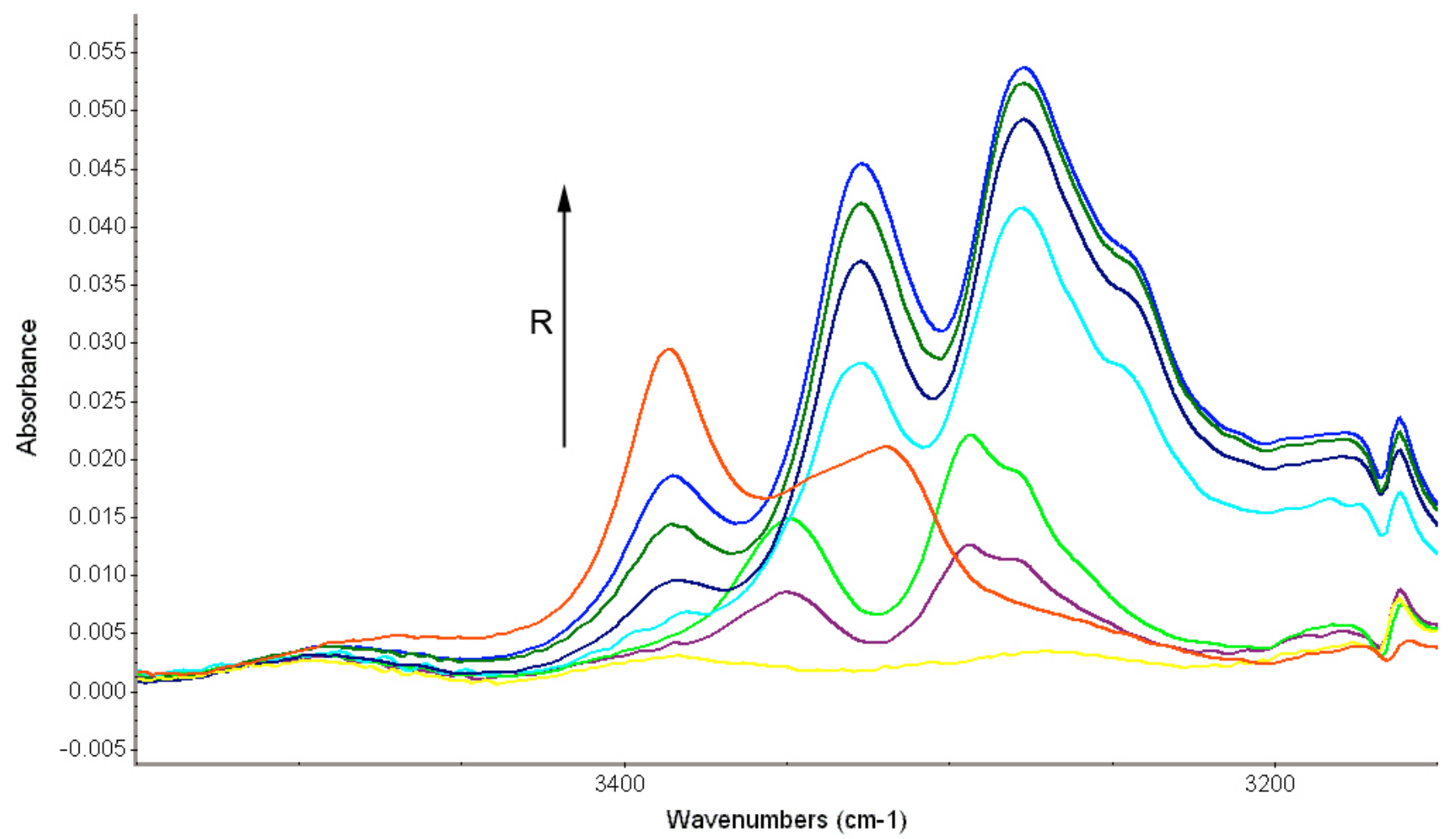

System La/trien: $\left[\mathrm{La}^{3+}\right] \sim 33 \mathrm{mmol} \mathrm{dm}{ }^{-3} ; \mathrm{R}=[\operatorname{trien}] /\left[\mathrm{La}^{3+}\right]=0.0,0.5,1.0,2.0,3.0,4.0,5.0$. Red spectrum: solution $195 \mathrm{mmol}$ $\mathrm{dm}^{-3}$ of trien in AN.

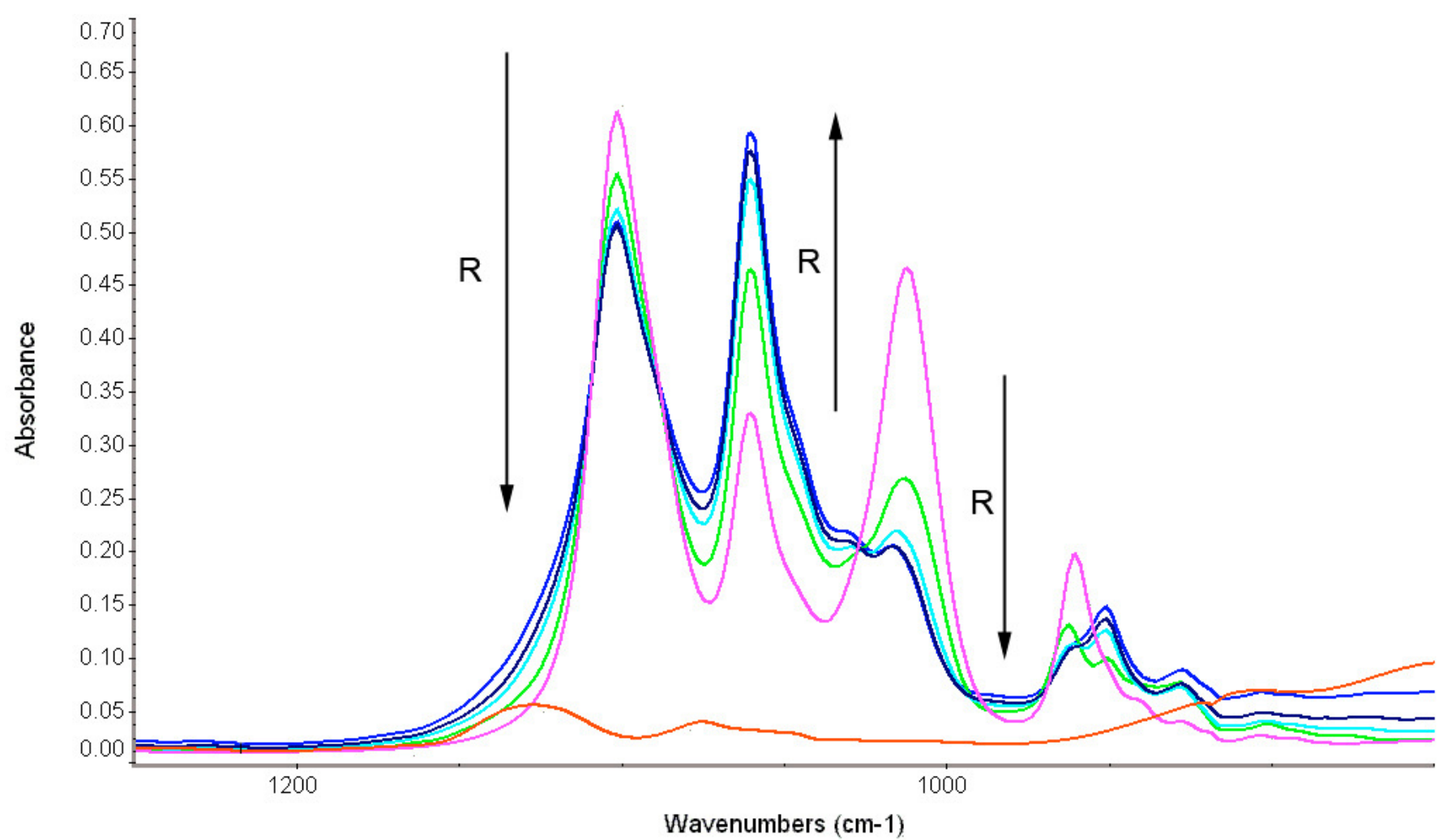

System La/trien: $\left[\mathrm{La}^{3+}\right] \sim 33 \mathrm{mmol} \mathrm{dm}{ }^{-3} ; \mathrm{R}=[\operatorname{trien}] /\left[\mathrm{La}^{3+}\right]=0.0,1.0,2.0,3.0,5.0$. Red spectrum: solution $195 \mathrm{mmol} \mathrm{dm}^{-3}$ of trien in AN. 


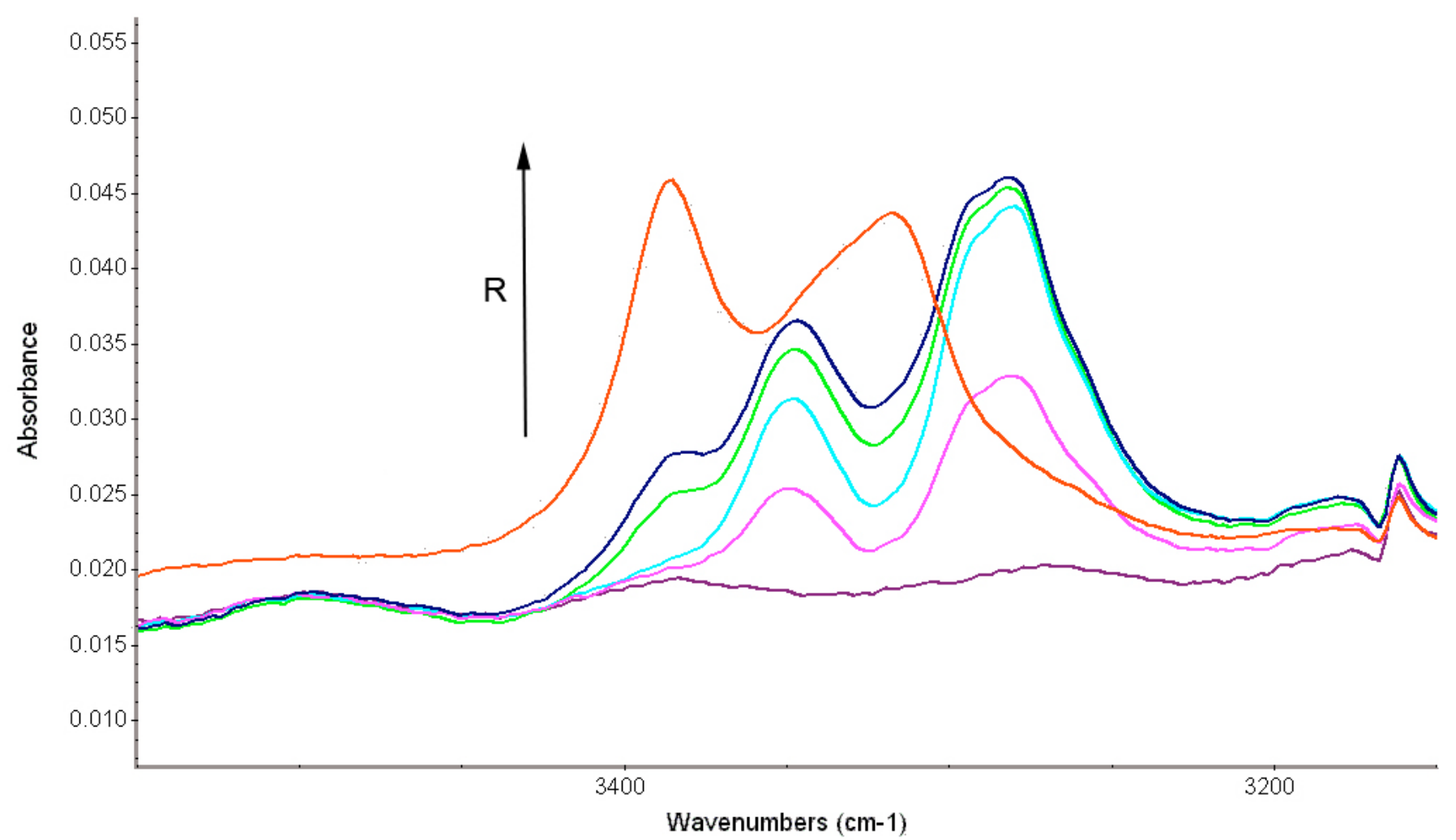

System La/tetren: $\left[\mathrm{La}^{3+}\right] \sim 33 \mathrm{mmol} \mathrm{dm}{ }^{-3} ; \mathrm{R}=[$ tetren $] /\left[\mathrm{La}^{3+}\right]=0.0,0.5,1.0,2.0,2.5$. Red spectrum: solution $174 \mathrm{mmol} \mathrm{dm}^{-3}$ of tetren in AN.

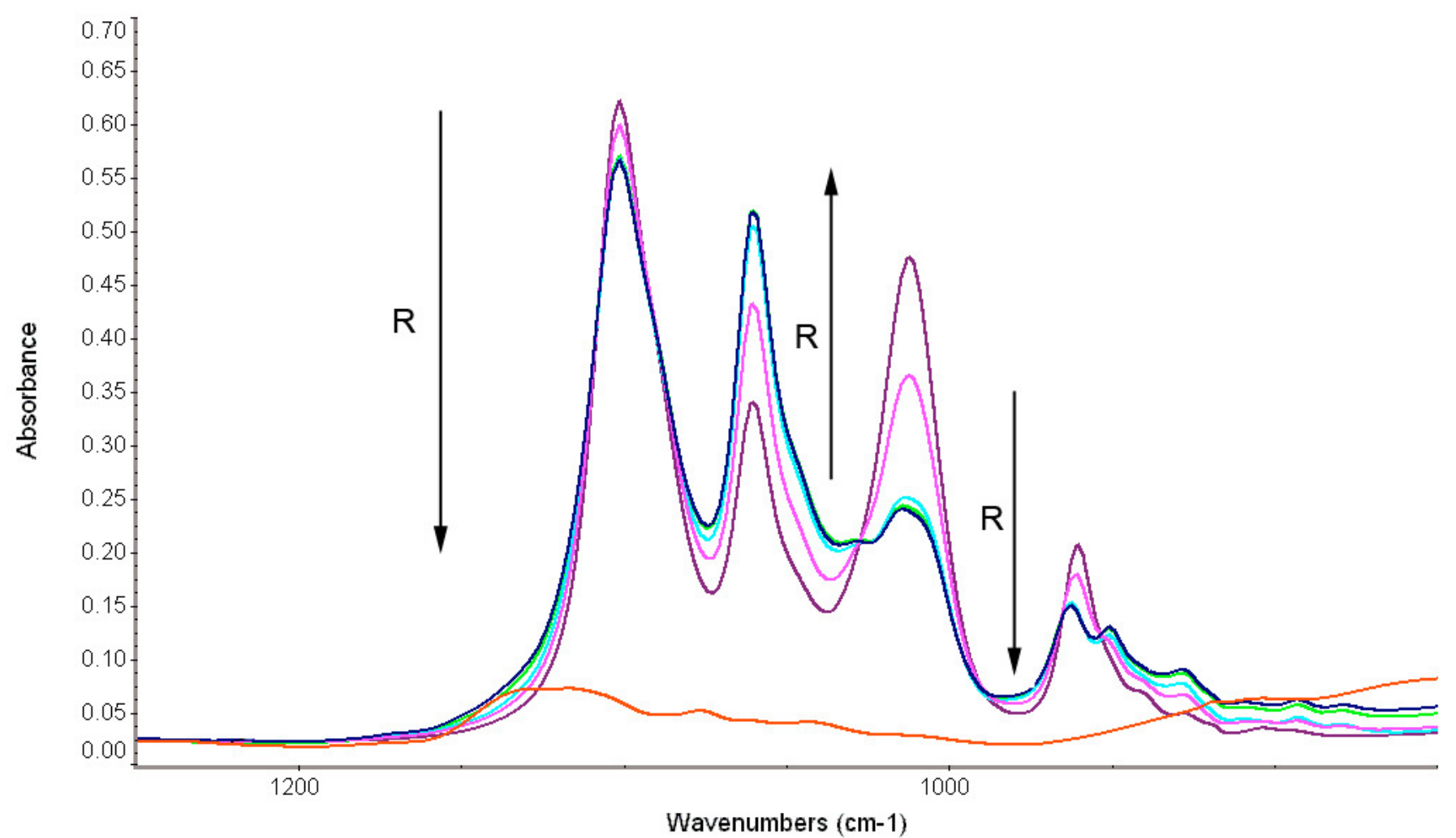

System La/tetren: $\left[\mathrm{La}^{3+}\right] \sim 33 \mathrm{mmol} \mathrm{dm}{ }^{-3} ; \mathrm{R}=[$ tetren $] /\left[\mathrm{La}^{3+}\right]=0.0,0.5,1.0,2.0,2.5$. Red spectrum: solution $174 \mathrm{mmol} \mathrm{dm}^{-3}$ of tetren in AN.

FIGURE S15 


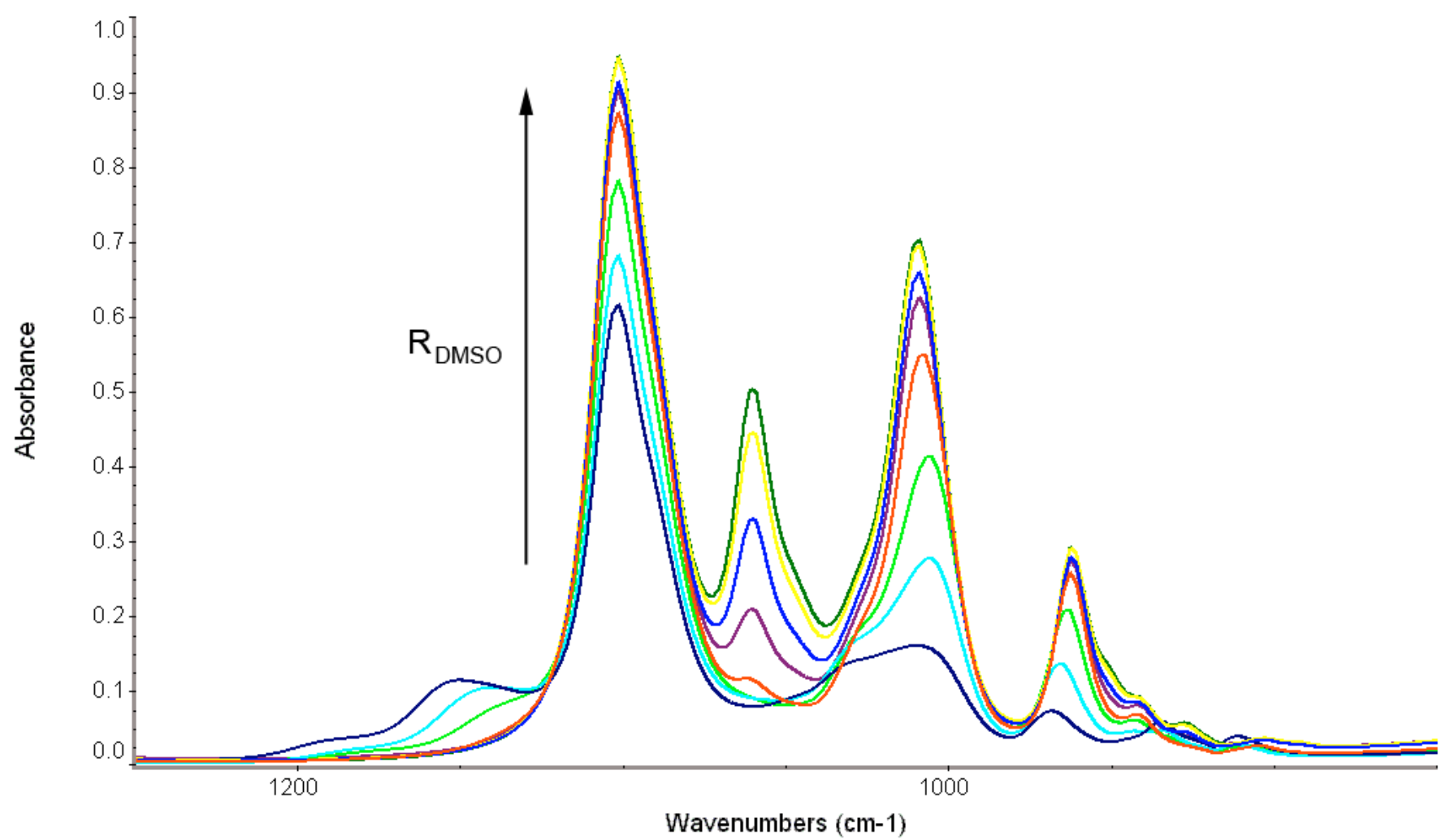

System Eu/DMSO in anhydrous AN: $\left[\mathrm{Eu}^{3+}\right] \sim 50 \mathrm{mmol} \mathrm{dm}^{-3} ; \mathrm{R}_{\mathrm{DMSO}}=[\mathrm{DMSO}] /\left[\mathrm{Eu}^{3+}\right]=2.0,4.0,6.0,8.0,10.0,12.0,14.0$, 15.0 .

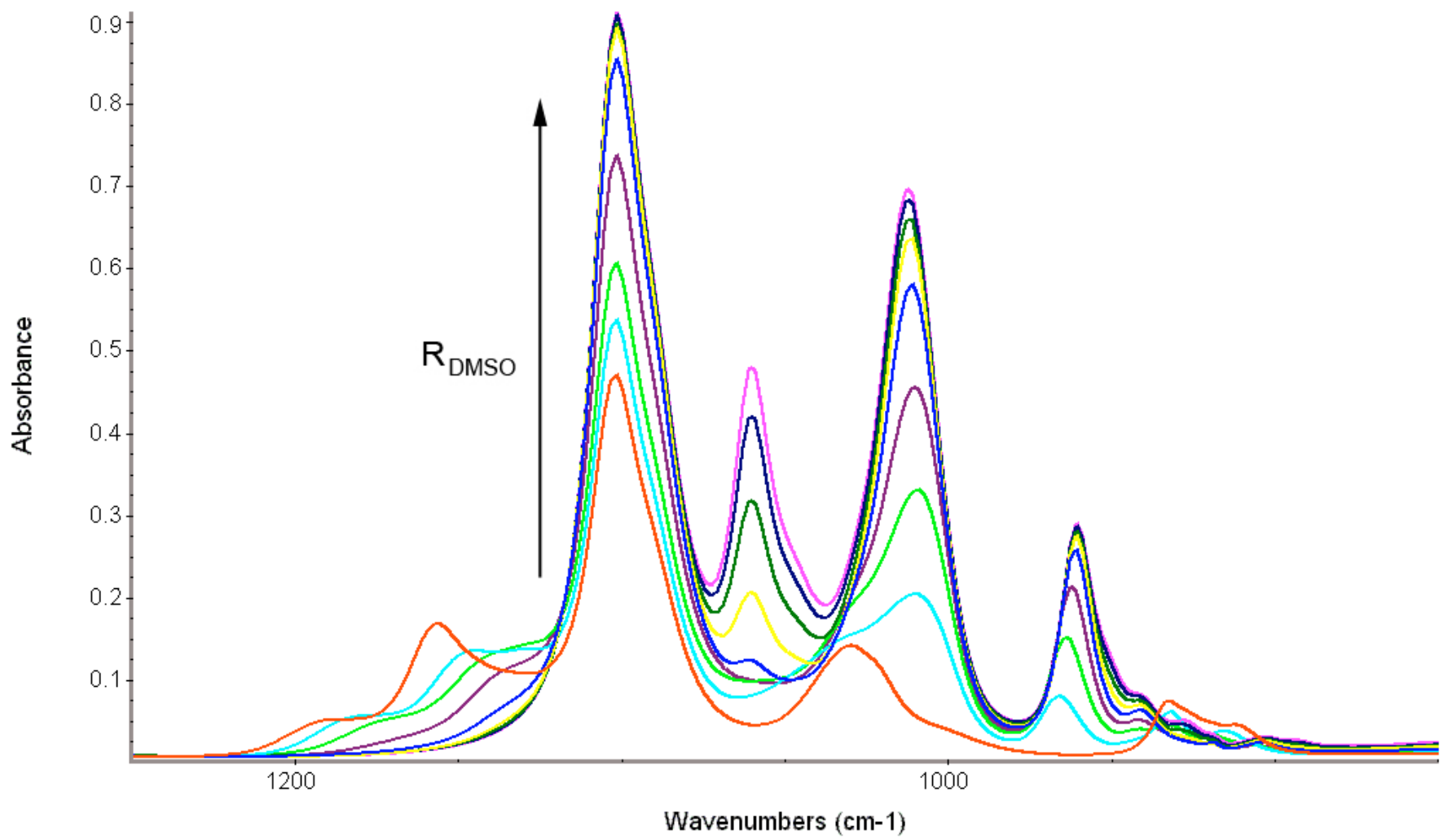

System La/DMSO in anhydrous AN: $\left[\mathrm{La}^{3+}\right] \sim 50 \mathrm{mmol} \mathrm{dm}{ }^{-3} ; \mathrm{R}_{\mathrm{DMSO}}=[\mathrm{DMSO}] /\left[\mathrm{Eu}^{3+}\right]=0.0,2.0,4.0,6.0,8.0,10.0,12.0,14.0$, 15.0 . 
Table S1. Average number of DMSO molecules coordinated to the lanthanides(III) $\left(\mathrm{NC}_{\mathrm{DMSO}}\right)$ in AN containing small amounts of DMSO. [Ln] $]^{3+} \approx 33 \mathrm{mmol} \mathrm{dm}^{-3}$; $[\mathrm{DMSO}] /\left[\mathrm{Ln}^{3+}\right]=15$. For each system, $\mathrm{R}$ is the stoichiometric ratio $[$ amine $] /\left[\mathrm{Ln}^{3+}\right]$ in solution.

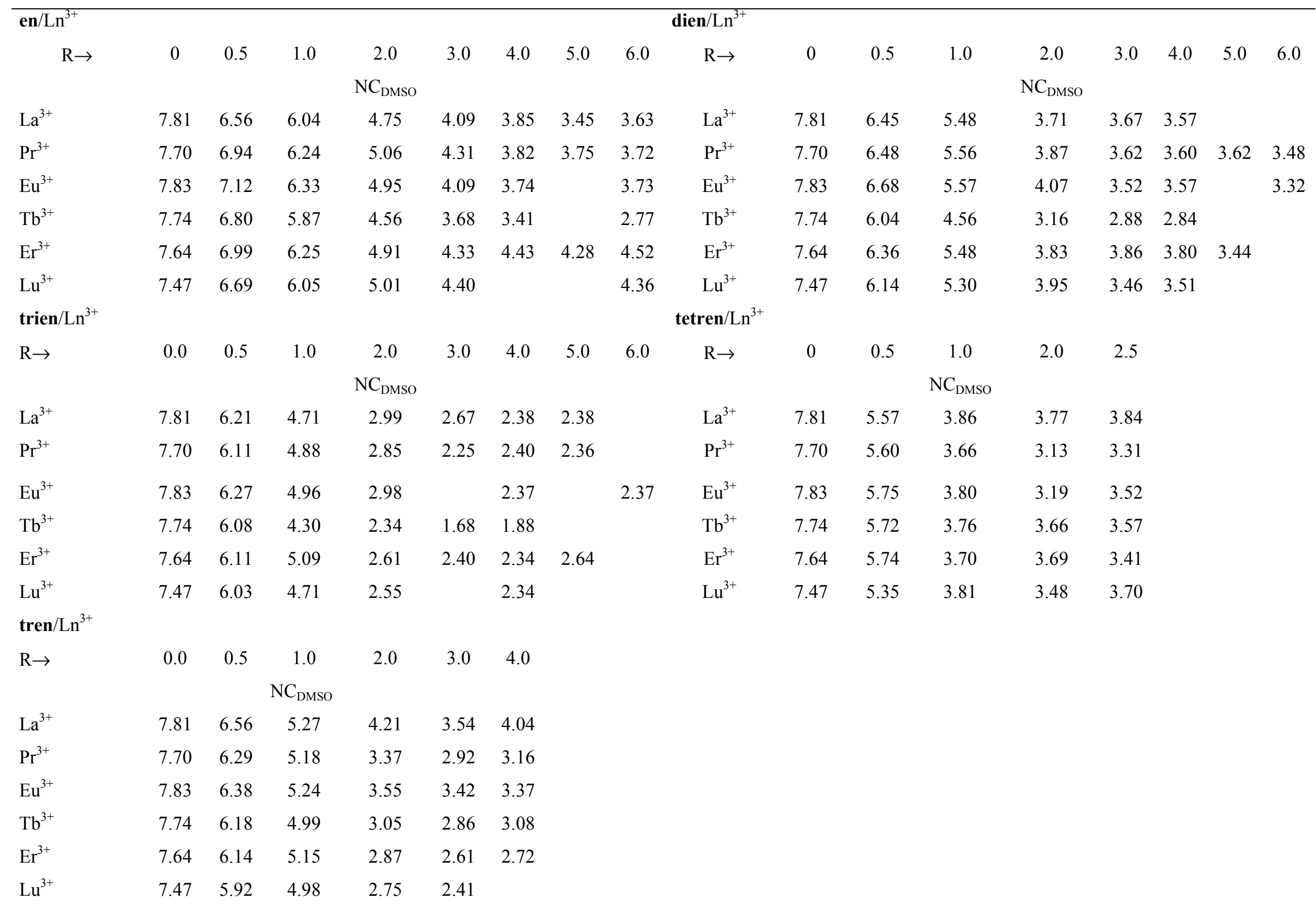

